Similarly, Einstein is linked indirectly with Mileva's academic failures. There is even a suggestion by the authors that Einstein beat Mileva. Sometimes the authors cite conflicting evidence for Einstein's extramarital liaisons during his second marriage to cousin Elsa. For example, after recounting a number of Einstein's liaisons during the 1920s in Berlin they quote Konrad Wachsmann, the architect who designed Einstein's summer house at Caputh (where some of the romantic meetings occurred), to the effect that the liaisons were "almost without exception" platonic. The authors do cite convincing evidence for certain of Einstein's affairs. In general their strategy is to weave selected passages from correspondence with reminiscences of Einstein from sometimes more than 40 years earlier in order to paint an unflattering picture.

Let's assume all this is true. Does it add to our understanding of Einstein' creativity or his science? This point is never addressed. Highfield and Carter are uninformative on such key issues and generally on what Einstein was up against scientifically in 1905. As a consequence, their narrative lacks the key line that they are telling us about a central figure in the history of ideas. It is like writing about Winston Churchill's life during 1940-45 without mentioning the Second World War. The authors offer us a disembodied figure, who becomes the subject of tabloid sensationalism. After all, maybe the worst possible scenario for Einstein's personal life was essential for his creativity, like Picasso's?

The titillating sensationalistic aspects of Einstein's correspondence aside, the critical portion for serious researchers interested in scientific creativity and not gossip, innuendo and rumour, are the early letters to Mileva (snippets are quoted by Highfield and Carter along with their interpretations - for the complete letters see J. Renn and R. Schulmann (eds) Albert Einstein and Mileva Marić: The Love Letters, Princeton University Press, 1992; for a review, see Nature 360, 377-378 (1992)), in addition to other material relating to his life during $1902-$ 09 . With proper analysis they could reveal how his personal life affected his scientific work. Is this not what we expect of the artist, musician or writer? Einstein's life as a young man is the stuff of which movies are made.

Arthur 1. Miller is in the Department of History, Philosophy and Communication of Science, University College London, Gower Street, London WC1 6BT, UK.

- Einstein: A Life in Science by Michael White and John Gribbin has just been published by Simon and Schuster, price £16.99.

\title{
Science's new language
}

DavidKnight

The Enlightenment of Matter: The Definition of Chemistry from Agricola to Lavoisier. By Marco Beretta. Watson Publishing International: 1993. Pp. 396. $\$ 49.95$.

LAVOISIER was beheaded in May 1794, and the event will be marked, if not celebrated, by conferences and publications, of which Marco Beretta's is one of the first. $\mathrm{He}$ is an Italian working in Sweden and writing in English, and has an excellent command of the French sources; he is therefore excellently placed to emphasize the new language that Lavoisier provided for chemistry, and its spread throughout Europe in the years

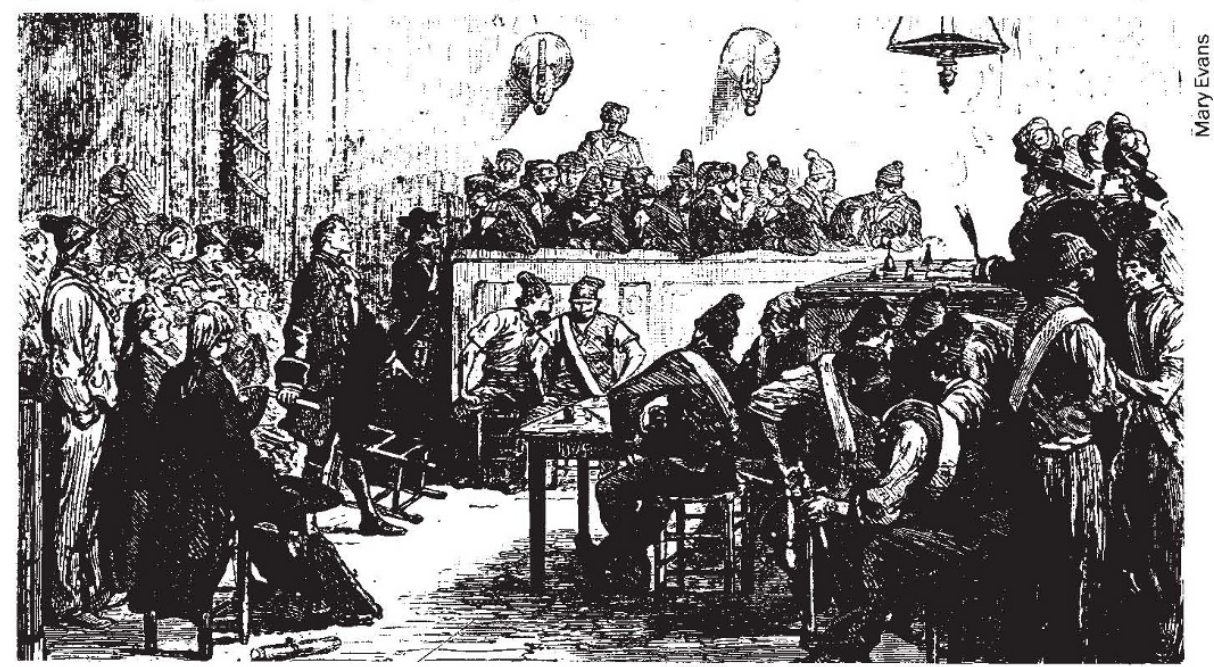

Lavoisier before the revolutionary tribunal that sentenced him to the guillotine in 1794.

between 1787 and 1800. Torbern Bergman and Guyton de Morveau have both in the past been given much of the credit for the new nomenclature, and Lavoisier's associates preferred to think of the new chemistry as a collective French achievement. But Beretta sees the achievement as essentially Lavoisier's, and the new language as crucial rather than as a convenient appendage to a new theory.

Lavoisier's great Traité élémentaire de chimie appeared in 1789 , and he was very conscious that his chemical revolution was simultaneous with the political revolution around him. This eventually cost him his life, as a prominent and extremely wealthy tax collector. Indeed, this was the first major transformation in the sciences to be described by participants as a revolution. The idea that such sharp discontinuities, like the catastrophes prominent in the geology of Lavoisier's period, make up the history of science is a crucial feature of Thomas Kuhn's philosophy of science. He stresses the differences in the terms and very language used before and after some heroic figure has transformed a science, accounting for earlier anomalies and persuading his colleagues to see things his or her way. This makes Lavoisier's revolution, where a new language was devised to transform a Baconian science into one having a clear and deductive structure, particularly instructive - perhaps indeed paradigmatic. Certainly Lavoisier's approach, example and language formed what Kuhn calls the paradigm within which the next generation worked.

Nevertheless, most students of the period have concentrated on Lavoisier's demonstration that the older view, that anything that would burn contained phlogiston, was incoherent. He replaced this with the theory that burning meant combination with oxygen, which had at first been called vital air, or eminently respirable air, or dephlogisticated air. Beretta emphasizes Lavoisier's respect for G. E. Stahl and his phlogiston theory, which had brought order into chemistry and formed a necessary stage in its development; and his preoccupation with scientific language. In the Traité, there is reference to E. B. Condillac and his writings on language, which were developed from those of John Locke; but for Beretta this is a clue to a most important part of Lavoisier's thinking.

In 1787 the treatise Nomenclature chimique was published, with Guyton's name first in the list of authors, and Lavoisier's second; it has often been supposed that this indicated their importance, but Beretta shows that the four authors were in fact listed in order of age. For him, this book represents Lavoisier's scheme, beautifully calculated to make the new theory palatable, and indeed almost inevitable; but very bold. One of his exemplars was Linnaeus, whose system of naming plants and animals had brought order into natural history. Linnaeus based his procedure on external characters: 
Lavoisier wanted to go deeper.

Here indeed he went astray famously over oxygen, which he named from Greek roots believing it to be the generator of acidity. His etymology came in for some attacks, but much more important was the basis for this name in a generalization from the known acids. First hydrogen sulphide and hydrogen cyanide, and then much more seriously the very strong acid from sea salt, turned out to contain no detectable oxygen when carefully analysed in the absence of water; Humphry Davy in 1810 concluded that they contained none. Oxygen was therefore a misnomer, and the French theory "the baseless fabric of a vision": to accuse the French of calling up cloud-capped towers and gorgeous palaces when they should have been doing sober science was a great pleasure to an Englishman and his listeners in wartime.

All science is open to falsification, and even Lavoisier did not get it all right; but Beretta is critical of Britons in the eighteenth century who saw language in science as a matter of conventions only, and chemistry as essentially a mass of facts. He is very interesting on the different national traditions in Europe in Lavoisier's day, and the way these affected the reception of the new chemistry. In Britain, the language was played down at first, but by 1800 its sheer convenience had prevailed. But perhaps we should note, as Beretta does not, that in medical practice 'antiphlogistic' remedies for reducing fever persisted into the 1820 s, and indeed Davy was given them in his last illness. Priestley, though politically pro-French and, therefore, ending his days as an exile in the United States in 1804, was firmly in favour of the phlogiston theory and nomenclature; but his example does not seem to have kept most English speakers from going along with the French. In Germany, political considerations were more important, and the French armies brought revolutionary principles in politics and chemistry with them.

The book ends with an appendix on alchemical imagery, with the message that this had nothing to do with chemistry. Certainly Beretta's ideal, like Lavoisier's, is a clear language, where analogies rather than metaphors are brought out. But we may feel that something was lost when the language of chemistry became so emphatically prosaic and algebraic, in accordance with Condillac's ideal; Samuel Taylor Coleridge went to Davy's lectures to improve his stock of metaphors, but the language was losing its resonance already. Beretta's book touches on many features of chemistry before 1800 , and is a stimulating addition to the literature.

David Knight is in the Department of Philosophy, University of Durham, Durham $D H 13 H N$, UK

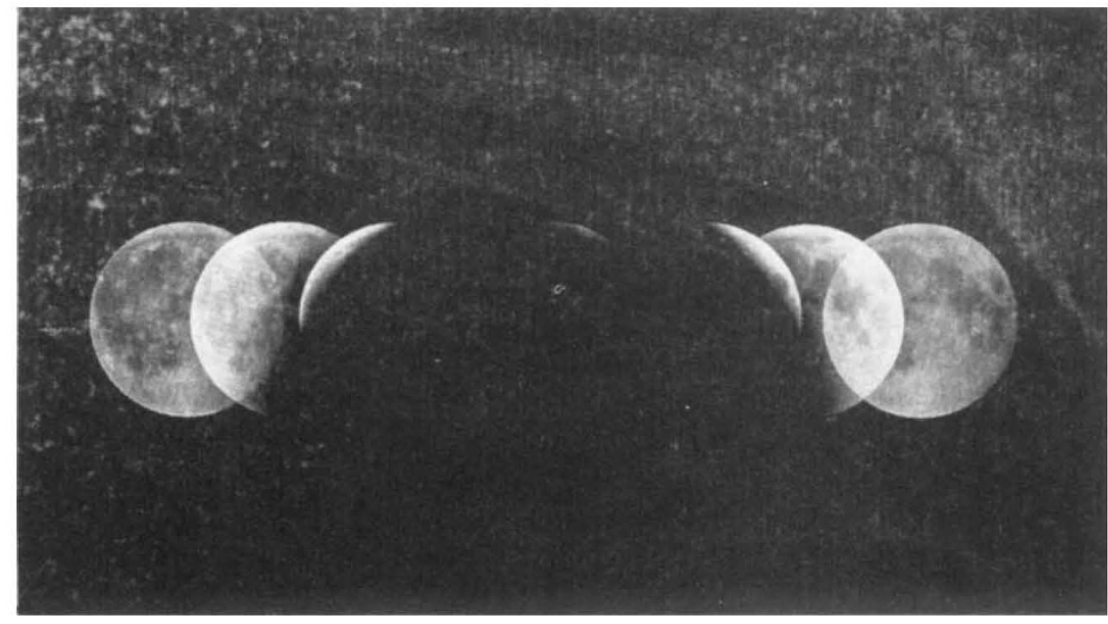

MuLTIPLE exposures of the Moon with the camera tracked at the rate the stars move across the sky reveal the shape of the Earth's shadow. This is one of many examples in a clear and practical guide to eclipse photography, The Cambridge Eclipse Photography Guide: How and Where to Photograph Solar and Lunar Eclipses. Cambridge University Press, £10.95, \$16.95.

\section{Discovery of the century?}

Joseph Silk

Wrinkles in Time. By George Smoot and Keay Davidson. Little, Brown: 1993. Pp. 321. £18.99.

Ripples in the Cosmos. By Michael Rowan-Robinson. Freeman: 1993. Pp. 224. £16.99, $\$ 22.45$.

Afterglow of Creation. By Marcus Chown. Arrow: 1993. Pp. 171. £5.99.

RARELY in the modern history of science has there been such a stir as that caused by the Cosmic Background Explorer (COBE) satellite discovery of ripples in the cosmic microwave background radiation. Front-page headlines in newspapers around the world heralded this announcement, accompanied by a picture that, it only later transpired, was mostly instrumental noise. Within hours of seeing the headlines on his way to Narita Airport in Tokyo, John Brockman, the highprofile literary agent, was on a payphone to George Smoot, principal investigator of the Differential Microwave Radiometer (DMR) experiment that mapped the ripples. A book was duly conceived, aided by "the largest deal in the history of science publishing" according to Marcus Chown, and has promptly been written, in collaboration with science journalist Keay Davidson. Wrinkles in Time is the outcome, a somewhat personal series of anecdotes about the vagaries of space astronomy.

What is remarkable about the DMR is that with off-the-shelf (in 1975) technology, Smoot was able to make two major breakthroughs in cosmology. He played a leading role in the group that flew the DMR aboard the U-2 spy plane, to spy on the heavens and discover the motion of our Galaxy relative to the cosmic microwave background radiation. The measured dipole anisotropy provided the first proof that the microwave background was of truly distant origin and likely to be the relic fireball from the Big Bang.

The slight deviation due to our motion was 1 part in 1,000 . Theorists had predicted that at a level of 1 part in 100,000 , one ought to be able to detect the blemishes in the microwave background that represent the seeds of large-scale structure. One sees the primordial fireball radiation when the Universe was only 300,000 years old; it provides a glimpse of the Universe before structure had formed. However, this increase in sensitivity required a space-borne platform, and Smoot nurtured the DMR experiment into a reincarnation on board the COBE satellite. The satellite was originally destined for the Space Shuttle, but the Challenger disaster made necessary a redesign and the experiment had to be reduced to fit into a Delta rocket that was launched four years ago. Fifteen years had elapsed since NASA's decision to proceed with COBE.

The wait was worthwhile. The farinfrared absolute spectrometer (FIRAS) carried on COBE, designed by John Mather, measured the most precise fit to a Planck function ever performed on a black body in the sky. The cosmic microwave background radiation is so perfect a black body that it could have originated only in the fiery furnace of the first months of the Big Bang. The DMR also performed according to plan. It mapped the entire sky at a resolution of 7 degrees, and measured slight deviations from uniform- 